\title{
Inhibition of bovine platelets aggregation in response to Hyalomma anatolicum salivary gland proteins/peptides
}

\author{
Surbhi ${ }^{1}$, Nirmal Sangwan ${ }^{1}$, Arun K. Sangwan ${ }^{2}$, Vijender Singh ${ }^{1}$ and Ankit Kumar ${ }^{3}$
}

1. Department of Veterinary Physiology and Biochemistry, Lala Lajpat Rai University of Veterinary \& Animal Sciences, Hisar - 125 004, Haryana, India; 2. Department of Veterinary Parasitology, Lala Lajpat Rai University of Veterinary \& Animal Sciences, Hisar - 125 004, Haryana, India; 3. Department of Veterinary Medicine, Lala Lajpat Rai University of Veterinary \& Animal Sciences, Hisar - 125 004, Haryana, India.

Corresponding author: Nirmal Sangwan, e-mail: nirmalsangwan@gmail.com,

S: surbhi804@gmail.com,AKS: sangwan_arun@hotmail.com, VS: vijender@luvas.edu.in, AK: ankitk813@gmail.com Received: 11-06-2016, Accepted: 07-10-2016, Published online: 17-11-2016

doi: 10.14202/vetworld.2016.1264-1268 How to cite this article: Surbhi, Sangwan N, Sangwan AK, Singh V, Kumar A (2016) Inhibition of bovine platelets aggregation in response to Hyalomma anatolicum salivary gland proteins/peptides, Veterinary World, 9(11): 1264-1268.

\begin{abstract}
Aim: Ticks are obligate ectoparasites that have an impact on wide range of vertebrates and also act as a potential vector for the transmission of tropical theileriosis, babesiosis, etc., causing significant loss to livestock production worldwide. While feeding, they introduce their saliva containing different bioactive molecules into the host. These molecules have the capability to counteract the host hemostatic mechanism to suck host blood successfully. Therefore, the study was aimed to isolate anti-platelet aggregating peptides from salivary gland extract (SGE) of Hyalomma anatolicum ticks, a commonly available tick in India.
\end{abstract}

Materials and Methods: Female H. anatolicum salivary glands were dissected out and SGE was prepared by homogenizing it in a suitable buffer under ice. Extract so obtained was fractionated by gel filtration chromatography using Sephacryl S-200 column. Total protein concentration in fractions was estimated and bovine platelets were isolated, stimulated with thrombin (positive control), treated with Gly-Pro-Arg-Pro amide (negative control) and with salivary gland fractions for identification of proteins/peptides having anti-platelet aggregating activities.

Results: Proteins/peptides present in various salivary gland fractions inhibited the bovine platelet aggregation and the percent inhibition ranged between $33 \%$ and $35.8 \%$.

Conclusion: The results suggests that the fractions of $H$. anatolicum salivary glands possess thrombin-induced anti-platelet aggregating activity and which could be further exploited for raising anti-tick vaccine and also for therapeutic purpose.

Keywords: anti-platelet aggregating proteins/peptides, gel filtration chromatography, Hyalomma anatolicum salivary gland, thrombin.

\section{Introduction}

Ticks are ectoparasites exclusively feed on host blood only. Their bite(s) results into blood loss, damage to hides and decreased milk production as the animals are under stress. They act as a leading vector for spirochetes, protozoa, viruses, and Rickettsiae as compared to any other arthropod [1], thus transmit a wide variety of pathogenic microorganisms affecting livestock, companion animals and humans. Important tickborne diseases include babesiosis, tropical theileriosis, tick-borne encephalitis, and Lyme disease. The global economic losses by tick infestation through direct production losses and the associated cost of treatment has been estimated at US\$14,000-18,000 million loss annually; while in India tick-borne diseases in livestock alone accounts for US\$498.7 million loss a annum [2].

Copyright: Surbhi, et al. Open Access. This article is distributed under the terms of the Creative Commons Attribution 4.0 International License (http://creativecommons.org/licenses/by/4.0/), which permits unrestricted use, distribution, and reproduction in any medium, provided you give appropriate credit to the original author(s) and the source, provide a link to the Creative Commons license, and indicate if changes were made. The Creative Commons Public Domain Dedication waiver (http://creativecommons.org/ publicdomain/zero/1.0/) applies to the data made available in this article, unless otherwise stated.
Ticks introduce their mouthparts into the host and generate a feeding cavity from which they feed on blood [3] and deposit saliva at the site of their attachment to a host to inhibit hemostasis, inflammation and innate and adaptive immune responses. Ticks need to overcome these defensive mechanisms to remain attached to the host for the entire feeding period to have successful blood meal [4]. These include direct collagen inhibitors [5], inhibitors of platelet adhesion to collagen [6], apyrases and catechol oxidases which are able to counteract the physiologic pro-hemostatic mechanisms that are triggered to avoid blood loss. Analyses of anti-platelet sialogenins may be useful tools in cell biology and may also have potential for therapeutic applications. A number of thrombin inhibitors have been isolated from ticks such as savignin from the soft ticks Ornithodoros savignyi [7] and ixin from Ixodes ricinus [8]. YY-39 was identified from many tick salivary glands found to inhibit adenosine diphosphate, thrombin, and TXA2 platelet aggregation [9].

Boophilin a multifunctional Kunitz protease inhibitor purified from the Midgut of Rhipicephalus microplus found to inhibit cathepsin G- and 
plasmin-induced platelet aggregation [10]. The ixodid ticks Hyalomma anatolicum is endemic in India infesting dairy animals responsible for transmitting Theileria annulata [11] causing tropical theileriosis. However, little information is available regarding anti-hemostatic substances found in salivary gland of $H$. anatolicum, the commonly available tick in India. The study was planned to isolate, fractionate the salivary gland proteins/peptides and to see the effects of proteins/peptides on bovine platelet aggregation.

\section{Materials and Methods}

\section{Ethical approval}

Research was conducted after due approval from Institutional Animal Ethics Committee.

\section{Sample collection}

$H$. anatolicum female ticks were collected and identified as per the key given by Miranpuri and Gill [12].

\section{Tick dissection and collection of salivary glands}

Ticks were washed with normal saline, immobilized individually on a Petri dish kept on ice by glue and incised along the dorsal-lateral margin using fine scalpel blade under a stereoscopic dissection microscope (Magnus MSZ-TR). Non-infected salivary glands were removed by fine tip forceps, transferred into 4-(2-hydroxyethyl)-1-piperazineethanesulfonic acid saline buffer, $\mathrm{pH}-7.0$ and stored in liquid nitrogen till analyzed.

\section{Salivary gland extract preparation}

Hundred pairs of ticks' salivary glands were pooled and homogenized using tissue homogenizer (T10 basic ULTRA-TURRAX ${ }^{\circledR}$, India) under cold conditions. The homogenate was centrifuged at 12,000 $\times g$ for $7 \mathrm{~min}$ at $4^{\circ} \mathrm{C}$, supernatant removed, filtered through Millex-GV Syringe Filter Unit, $25 \mathrm{~mm}$ polyvinylidene fluoride (PVDF) $22 \mu \mathrm{m}$ Sterile with Vent. The resulting filtrate was diluted to $2 \mathrm{ml}$ with $50 \mathrm{mM}$ Tris-Cl, $\mathrm{pH} 8.3$ and then used for fractionation, isolation and identification of anti-platelet aggregating factors from $H$. anatolicum salivary glands.

\section{Isolation of anti-platelet aggregating factors from the salivary glands}

The filtrate was applied to a Sephacryl S-200 gel filtration column $(1 \mathrm{~cm} \times 60 \mathrm{~cm})$ equilibrated with
$50 \mathrm{mM}$ Tris-HCL, $\mathrm{pH}-7.5$ with $100 \mathrm{mM} \mathrm{KCL}$ and eluted with $40 \mathrm{mM}$ Tris- $\mathrm{Cl}, \mathrm{pH}-7.5$, fractions were collected each of $1.5 \mathrm{ml}$. The column was calibrated with molecular weight markers from Sigma (alcohol dehydrogenase - $150 \mathrm{kDa}$; albumin - $66 \mathrm{kDa}$; carbonic anhydrase - $29 \mathrm{kDa}$; cytochrome C - $12.4 \mathrm{kDa}$; and the void volume determined with Blue Dextran - 2000 $\mathrm{kD})$. The approximate molecular weights of proteins were determined using a standard curve of $\mathrm{V}_{\mathrm{e}} / \mathrm{V}_{\mathrm{o}}$ against log molecular weight. Protein concentration of each fraction was estimated [13], using bovine serum albumin as standard.

\section{Platelets preparation}

Bovine blood was collected from buffalo calves maintained at Department of Veterinary Physiology and Biochemistry, Lala Lajpat Rai University of Veterinary and Animal Sciences (LUVAS), Hisar using $0.1 \mathrm{M}$ trisodium citrate as anticoagulant in 9:1 and platelet rich plasma (PRP) was obtained by centrifugation at $1000 \mathrm{rpm}$. Then, PRP was centrifuged at $4000 \mathrm{rpm}$ to get the platelet pellet. The platelet pellet was washed twice with Tyrode buffer "A" (with ethylether)-N,N'-tetraacetic acid [EGTA]), and then the final pellet was resuspended in the Tyrode buffer "B" (without EGTA), in a volume adjusted to give an OD of 0.15 at $650 \mathrm{~nm}$.

\section{Platelet aggregation assay}

Effect of different isolated protein fractions on platelet aggregation was measured using ELISA plate reader at $650 \mathrm{~nm}$ by the method followed by Francischetti et al. [14] with little modification. Platelets were incubated with Gly-Pro-Arg-Pro (1 $\mathrm{mM}$ ) amide as antagonist and isolated protein fractions for $10 \mathrm{~min}$ at $37^{\circ} \mathrm{C}$ in 96 well flat bottom plate. Then, the aggregation was initiated by adding thrombin $(0.5 \mathrm{nM})$ as agonist. Changes in platelet aggregation were monitored at $650 \mathrm{~nm}$ at every $5 \mathrm{~min}$ interval for $20 \mathrm{~min}$.

\section{Results}

A total of 120 gel filtration chromatographic fractions were collected and analyzed for total protein concentration which ranged from 0.7 to $85.2 \mu \mathrm{g} / \mathrm{ml}$ (Figure-1). Fractions having proteins were further analyzed for platelet aggregation inhibitory activities

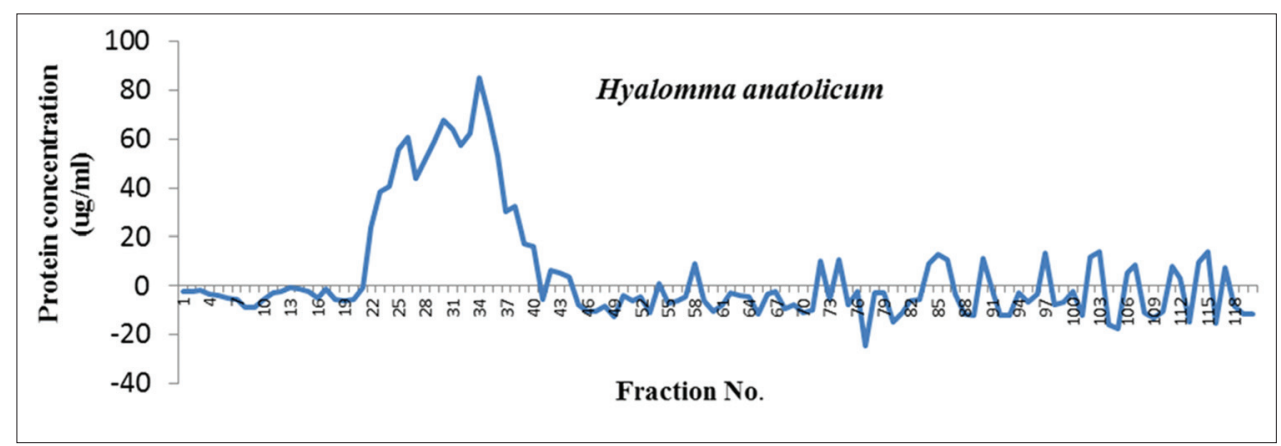

Figure-1: Total protein concentration of Hyalomma anatolicum salivary gland fractions collected by gel exclusion chromatography. 
already stimulated with thrombin. Effects of various $H$. anatolicum salivary protein fractions on bovine platelet aggregation inhibition are shown in Figure-2. It was observed that fraction nos. 28, 29, 30, 31, 32, $42,58,111$, and 112 having platelet aggregation inhibition activities nearly similar to that of antagonist-induced aggregation inhibition and was much higher as compared to agonist-induced platelet aggregation. The total protein concentration in these above-mentioned fractions was found to be 51.5, 58.8, 67.7, 63.9, 57.5, 6.2, 9.1, 7.9 and $3.3 \mu \mathrm{g} / \mathrm{ml}$, respectively. Percent platelet aggregation inhibition by $H$. anatolicum salivary gland fractions ranged from $33 \%$ to $35.8 \%$. The inhibition was comparatively less due to proteins in various fractions as compared to that of antagonist peptide where $38.3 \%$ inhibition was observed (Figure-3). The effects of individual protein fractions having the anti-platelet aggregating activities are shown in Figure-4. It was reported that various proteins present in different fractions behaved differently in terms of platelet aggregation inhibition when compared to that of agonist thrombin-stimulated platelet aggregation and antagonist-induced platelet inhibition. Fraction no. 30 and 112 had nearly similar activities to that of antagonist while the fraction no. 28 and 111 activity had slightly less inhibitory activity. The potency for the antithrombin effect of the tested compounds at $35.8 \%$ inhibition was the strongest for fraction no. $112(3.3 \mu \mathrm{g}$ protein $/ \mathrm{ml})$.

\section{Discussion}

H. anatolicum salivary gland selected fractions were found to inhibit bovine platelet aggregation which was stimulated by thrombin. When compared with the peptide (Gly-Pro-Arg-Pro) known to have platelet aggregation inhibitory activities, some of the fractions showed comparable inhibitory effect than the known inhibitory peptide while others showed the slightly less effects to that of inhibitory peptide. This inhibitory peptide is known to inhibit fibrin polymerization while thrombin is known to induce platelet aggregation via interaction among thrombin exosites and the substrates on platelet membrane, namely, proteins platelet activating receptors-1 (PAR-1) and PAR-4 [15,16]. Similarly, Nienaber et al. [7] reported the thrombin-induced aggregation inhibitor savignin from the soft tick O. savignyi while Hoffmann et al. [8] isolated ixin platelet inhibitor from I. ricinus. Ibelli et al. [17] characterizes Ixodes scapularis (Ixsc) IxscS-1E1, a blood meal-induced serine protease inhibitor from Ixsc tick saliva and was found to inhibit $23.4 \%$ thrombin-induced aggregation. De Queiroz et al. [18] isolated BmooAi, from Bothrops moojeni that inhibited platelet aggregation. Sanchez et al. [19] reported BarI, isolated from the venom of Bothrops barnetti found to dissolves fibrin clots made either from purified fibrinogen or from whole blood. In $H$. anatolicm maximum inhibitory activity was found to be in range of 33-35.8\% in different fractions. In this study, the inhibitory effects

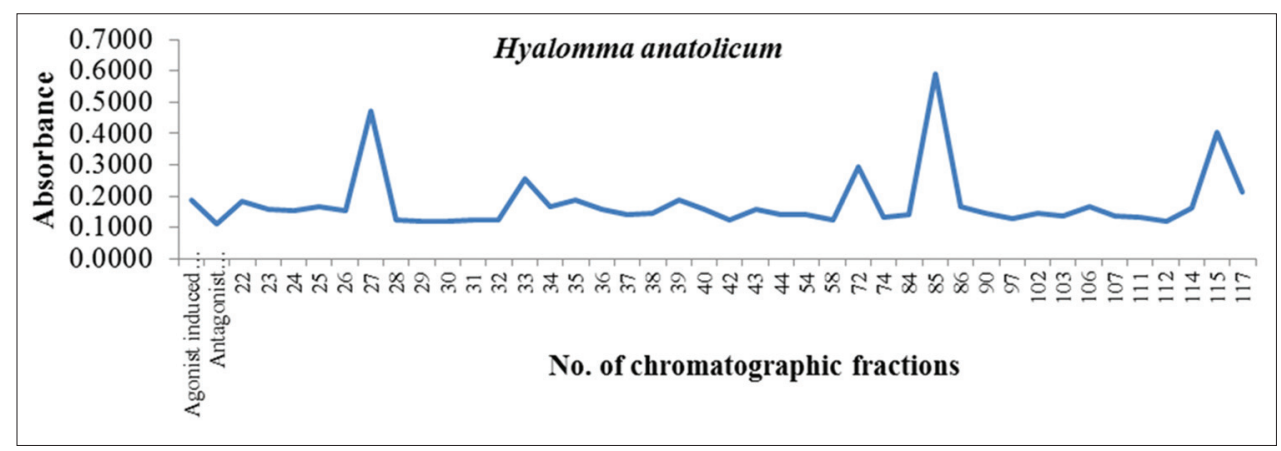

Figure-2: Effects of Hyalomma anatolicum salivary gland protein fractions on bovine platelet aggregation stimulated with thrombin.

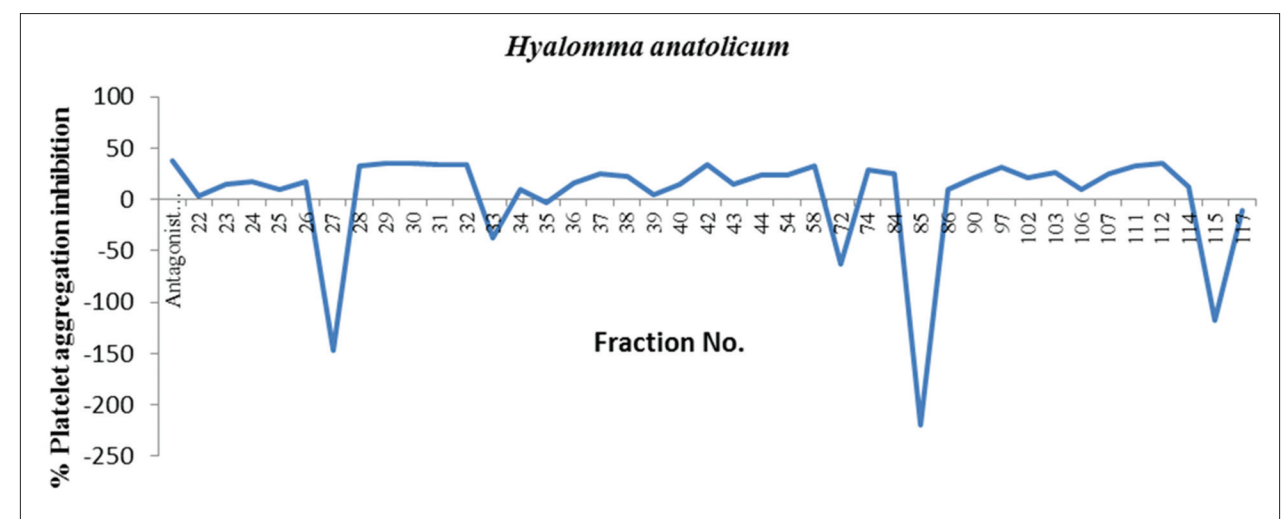

Figure-3: Percent platelet aggregation inhibition by Hyalomma anatolicum salivary gland protein fractions. 


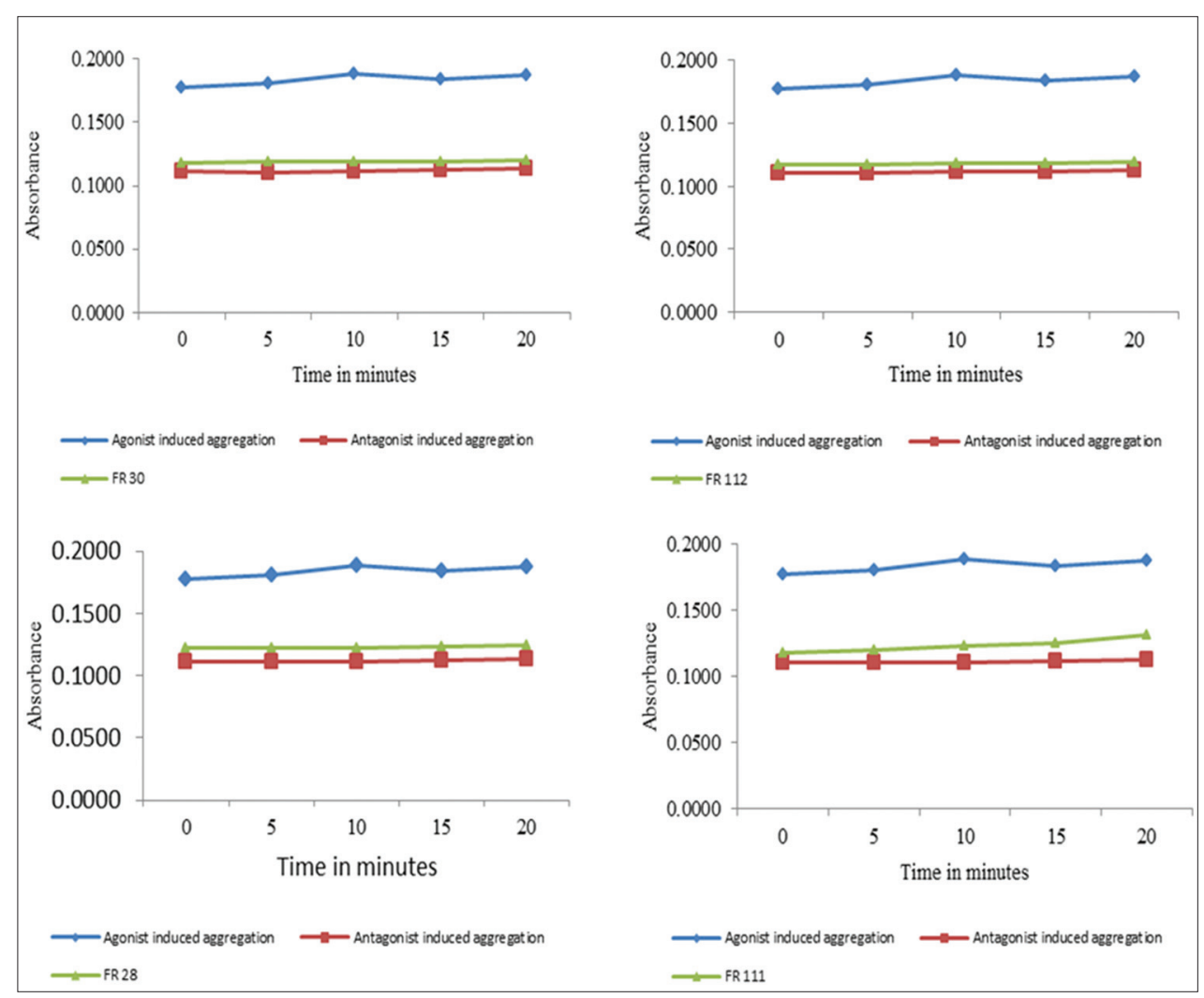

Figure-4: Activity of Hyalomma anatolicum salivary gland individual protein fractions on bovine platelet aggregation inhibition after stimulation with thrombin $(0.5 \mathrm{nM})$.

of proteins/peptides in various fractions can be either due to inhibition of fibrin polymerization or due to inhibition of action of thrombin exosites, PAR-1 and PAR-4 receptors which are mainly found in activated platelets for platelet plug formation at the site of vascular injury and thereby preventing the conversion of fibrinogen to fibrin.

\section{Conclusion}

A significant amount of platelet aggregation inhibitory proteins/peptides was found in salivary gland of Hyalomma anatolicum tick whose mechanism of action needs to be further exploited for raising anti-tick vaccines as well as for therapeutic purposes.

\section{Authors' Contributions}

NS designed the experiment, data analyses, preparation and final corrections of the manuscript. $\mathrm{S}$ and AKS collected the sample. AKS identified the tick species and contributed in the dissection of ticks. S performed the dissection of ticks, wet lab analyses, and data analyses. VS and AK helped during analysis. All authors participated in manuscript preparation. All authors read and approved the final manuscript.

\section{Acknowledgments}

The authors would like to thank the Head of the Department of Veterinary Physiology and Biochemistry, LUVAS, Hisar, Haryana, India, for generation of fund for the present study.

\section{Competing Interests}

The authors declare that they have no competing interests.

\section{References}

1. Jongejan, F. and Uilenberg, G. (2004) The global importance of ticks. Parasitology, 129: S3-S14.

2. Minjauw, L. and McLeod, A. (2003) Tick borne diseases and poverty. The impact of tick and tick borne diseases on the livelihoods of small-scale and marginal livestock owners in India and Eastern and Southern Africa. In: Research Report. DFID Animal health Programme. Centre for Tropical Veterinary Medicine, University of Edinburgh, UK.

3. Francischetti, I.M., Sa-Nunes, A., Mans, B.J., Santos, I.M. and Ribeiro, J.M. (2009) The role of saliva in tick feeding. Front. Biosci., 14: 2051-2088.

4. Chmelar, J., Calvo, E., Pedra, J.H., Francischetti, I.M. and Kotsyfakis, M. (2012) Tick salivary secretion as a source of antihemostatics. J. Proteomics, 75(13): 3842-3854.

5. Harsfalvi, J., Stassen, J.M., Hoylaerts, M.F., VanHoutte, E., Sawyer, R.T., Vermylen, J. and Deckmyn, H. (1995) Calin from Hirudo medicinalis, an inhibitor of von Willebrand factor binding to collagen under static and flow conditions. Blood, 85: 705-711.

6. Karczewski, J., Waxman, L., Endris, R.G. and Connolly, T.M. (1995) An inhibitor from the argasid tick Ornithodoros moubata of cell adhesion to collagen. Biochem. Biophys. Res. Commun., 208(2): 532-541.

7. Nienaber, J., Gaspar, A.R.M. and Neitz, A.W. (1999) Savignin, a potent thrombin inhibitor isolated from the salivary glands of the tick Ornithodoros savignyi (Acari: Argasidae). Exp. Parasitol., 20: 583-598.

8. Hoffmann, A., Walsmann, P., Riesener, G., Paintz, M. and Markwardt, F. (1991) Isolation and characterization of a thrombin inhibitor from the tick Ixodes ricinus. Pharmazie, 
46: $209-212$.

9. $\quad$ Tang, J., Fang, Y., Han, Y., Bai, X., Yan, X., Zhang, Y., Lai, R. and Zhang, Z. (2015) YY-39, a tick anti-thrombosis peptide containing RGD domain. Peptides, 68: 99-104.

10. Assumpção, T.C., Ma, D., Mizurini, D.M., Kini, R.M., Ribeiro, J.M.C., Kotsyfakis, M. and Francischetti, I.M.B. (2016) In vitro mode of action and anti-thrombotic activity of boophilin, a multifunctional Kunitz protease inhibitor from the midgut of a tick vector of babesiosis, Rhipicephalus microplus. PLoS Negl. Trop. Dis., 10(1): e0004298.

11. Ghosh, S., Bansal, G.C., Gupta, S.C., Ray, D.D., Khan, Q.M., Irshad, H., Shahiduzzaman, M.D., Seitzer, U. and Ahmed, J.S. (2007) Status of tick distribution in Bangladesh, India and Pakistan. Parasitol. Res., 101: 207-216.

12. Miranpuri, G.S. and Gill, H.S. (1983) Ticks of India. Lindsay \& Macleod, Edinburgh.

13. Bradford, M.M. (1976) A rapid and sensitive method for the quantitation of microgram quantities of protein utilizing the principle of protein-dye binding. Anal. Biochem., 72: $248-254$.

14. Francischetti, I.M., Ribeiro, J.M., Champagne, D. and Andersen, J. (2000), Purification, cloning, expression, and mechanism of action of a novel platelet aggregation inhibitor from the salivary gland of the bloodsucking bug,
Rhodnius prolixus. J. Biol. Chem., 275: 12639-12650.

15. Ofosu, F.A. (2003) Protease activated receptors 1 and 4 govern the responses of human platelets to thrombin. Tranfus. Apher. Sci., 28: 265-268.

16. Huntigton, J.A. (2005) Molecular recognition mechanisms of thrombin. J. Thromb. Haemost., 3: 1861-1872.

17. Ibelli, A.M., Kim, T.K., Hill, C.C., Lewis, L.A., Bakshi, M., Miller, S., Porter, L. and Mulenga, A. (2014) A blood meal-induced Ixodes scapularis tick saliva serpin inhibits trypsin and thrombin, and interferes with platelet aggregation and blood clotting. Int. J. Parasitol., 44(6): 369-379.

18. De Queiroz, M.R., Mamede, C.C., de Morais, N.C., Fonseca, K.C., de Sousa, B.B., Migliorini, T.M., Pereira, D.F., Stanziola, L., Calderon, L.A., SimõesSilva, R., Soares, A.M. and De Oliveira, F. (2014) Purification and characterization of BmooAi: A new toxin from Bothrops moojeni snake venom that inhibitsplatelet aggregation. Biomed. Res. Int., 2014: 920942-920947.

19. Sanchez, E.F., Richardson, M., Gremski, L.H., Veiga, S.S., Yarleque, A., Niland, S., Lima, A.M., Estevao-Costa, M.I. and Eble, J.A. (2016) A novel fibrinolytic metalloproteinase, barnettlysin-I from Bothrops barnetti (barnett's pitviper) snake venom with antiplatelet properties. Biochim. Biophys. Acta, 1860(3): 542-556.

\section{$* * * * * * * *$}

